\title{
La negra Angustias, una Doña Bárbara mexicana
}

H ACE diez años se publicó en México La negra Angustias, de 1 Francisco Rojas González. Aunque ganó el Premio Nacional de Literatura de 1944, esta novela todavía no ha sido estudiada detenidamente, ni siquiera en México. Si se consideran el gran éxito de Doña Bárbara y el intenso interés por la novela de la 'Revolución mexicana, resulta incomprensible el desconocimiento de La negra Angustias, que reúne algunos de los mejores elementos, tanto de la épica Doña Bárbara como de las obras de Azuela, López y Fuentes y sus contemporáneos.

Francisco Rojas González nació en 1903, en el Estado de Jalisco, y murió prematuramente, en 1951. Su reputación literaria se basa principalmente en La negra Angustias (1944), otra novela Lola Casanova (1947) y varias colecciones de cuentos, de las cuales sobresale El diosero (1952). Toda su obra revela la influencia de su trabajo etnológico en el Instituto de Investigaciones Sociales de la Universidad Nacional.

Para hacer una comparación entre La negra Angustias y Doña Bárbara, dividamos la vida de las protagonistas en cinco momentos:

1. Los origenes;

2. Las causas de su rebeldía;

3. El dominio sobre los hombres;

4. La derrota por el hombre culto;

5. "Las cosas vuelven al lugar de donde salieron." 1 
Tanto Angustias como la "dañera" venezolana tienen sangre mezclada. La mexicana resultó del matrimonio de una mujer blanca y fina con un mulato salteador, Antón Farrera. En las dos protagonistas el odio a los hombres tiene sus raíces en el mismo nacimiento. Doña Bárbara, sabiendo que fué "el fruto engendrado por la violencia del blanco aventurero en la sombría sensualidad de la india", ${ }^{2}$ se exaspera al dar a luz ella misma. Sus instintos maternos se desvanecen por completo frente al pensamiento de que este nacimiento representa otra "victoria del macho, una nueva violencia sufrida". 3

De la misma manera, la negra Angustias, sabiendo que su madre murió después de dar a luz, se enfurece ante la supremacía del macho. De niña, ella cuida las cabras de su padre. Siempre que las sorprende al entregarse a los machos, interrumpe violentamente sus juegos eróticos. Cuando su cabra consentida muere después de parir, su odio hacia los machos se intensifica a tal grado, que los persigue hasta clavarles gruesas espinas y golpearlos con piedras filudas. Más tarde, cuando Angustias ya es "coronela" en la Revolución, una mujer le ruega que interceda por su novio preso. Angustias la escucha pacientemente hasta que la "señorita" le confiesa que está encinta. Frente a esta nueva manifestación de la supremacía masculina, la Negra perdona al preso, pero manda azotar severamente a la "señorita". A pesar de la brutalidad de la mulata, el autor nos da a entender que en realidad se siente avergonzada de su propia fiereza y que envidia a la futura madre. Este deseo subconsciente de experimentar sentimientos femeninos, que también se encuentra 七n doña Bárbara, es lo único que explica la transformación subsecuente de las dos protagonistas.

A este odio casi innato añádese en las dos mujeres la amargura que proviene de su primer contacto con los hombres. Criada en una piragua por el viejo piloto Eustaquio, Barbarita estaba expuesta continuamente a las "rudas manotadas" y los "besos que sabían a aguardiente" 4 de los cinco hombres de la tripulación. Cuando tenía quince años, esta época de su vida terminó con la rebelión contra el capitán, celebrada con "el festín de su doncellez". ${ }^{5}$ El viejo Eustaquio la rescató y la llevó a vivir en un pueblito. Alli Bárbara se apasiona tanto por la brujería que "no vive sino para apoderarse de los secretos que se relacionan con el hechizamiento del varón." 6 La belleza de la "guaricha" perturba la paz del pueblo, y Eustaquio 
tiene que llevársela en su bongo. Doña Bárbara comienza a vengarse de los hombres echando a perder la carrera de Lorenzo Barquero, el brillante alumno de derecho que no sabe resistir la llamada de los llanos, a pesar de su cultura caraqueña.

Aunque los motivos de la rebeldía de Angustias no son idénticos a los de la venezolana, son tan semejantes que se puede afirmar con relativa seguridad que Rojas González se inspiró en esta obra maestra de Gallegos. Muerta su madre y encarcelado su padre por salteador, la "prietita" se cría con la bruja doña Crescencia. Aunque Angustias no se aficiona a la brujería tanto como Bárbara, es feliz en la casa de la hechicera, quien no puede menos que dejar una huella en la mente muy impresionable de la mulata. Cuando Angustias tiene doce años, su padre regresa de la penitenciaría y la lleva a vivir en una choza solitaria. Al llegar a ser apetecible por los hombres, Angustias tiene miedo de las miradas lascivas de los arrieros que pasan por los cerros. Cuando la mulata rechaza la oferta de matrimonio de un joven decente, incurre en la ira del pueblo, lo cual constituye otro punto de contacto con los origenes de doña Bárbara. La adolescencia de Angustias termina tan violentamente como la de Bárbara. Fastidiada de ser acosada constantemente por un boyero, Angustias acaba por matarlo. Al darse cuenta de que cl puñal de su padre se ha perdido en el fondo de la barranca, huye despavorida del pueblo. Después de vagar en el bosque sin rumbo fijo, aterrada se deja vencer por la fatiga y se desploma bajo un árbol, a dormir.

Su pesadilla, en la cual se vió atacada por un macho cabrío jadeante, se interrumpe por las carcajadas de unos hombres a caballo que han topado con la "bella durmiente" durante su ronda. Por poco sufre Angustias la misma humillación que amargó tanto la vida de Bárbara. Sólo la intervención del Güitlacoche impide que los jinetes celebren el descubrimiento de Angustias, con el "festín de su doncellez". Les advierte que semejante acción, sin la presencia de Efrén el Picado, su jefe donjuanesco, sería una indiscreción tremenda. Llevan a la asustada muchacha al rancho de Efrén, donde éste no tarda en emprender su conquista. Sin embargo, sus deseos de hacerla su nueva amante no se llevan a cabo porque celebra por anticipado su éxito, con demasiadas copas. Aprovechándose de la borrachera de Efrén y de los celos de doña Chole, su amante, Angus- 
tias Farrera se escapa con el Güitlacoche, quien le of rece a la bella mulata hacer todo lo que ella quiera. Cuando el Güitlacoche le dice que van rumbo a Real de Animas, un antiguo pueblo minero, la Negra comienza a transformarse. Recuerda que está en el camino donde su padre Antón Farrera, asaltaba las diligencias y las recuas. Su odio a los hombres, el identificarse con las hazañas de su padre, la brusca reacción por el reciente episodio espeluznante y el carácter sumiso del Güitlacoche - todo contribuye a la repentina sensación de poder que corre por su cuerpo. Comprueba la fuerza de este poder al no hacer caso de los requiebros amorosos de su compañero y al mandarle bruscamente, al mismo tiempo, que baje de su caballo para componerle un estribo que se le ha aflojado. Al llegar a Real de Animas, Angustias oye por primera vez noticias de la Revolución. Despiertan su imaginación los relatos sobre el movimiento zapatista, con su lema de "tierra y libertad", y no puede menos que simpatizar con la rebelión de "los probes" contra los abusos que sufren a manos de la sociedad porfiriana. Mediante la evocación de los recuerdos de su padre, muy querido por los pobres a causa de sus características de Robin Hood, la Negra logra reunir un grupo de hombres, les incita con una arenga revolucionaria, se nombra "coronela" y se va con su grupo, para juntarse con las fuerzas zapatistas en Jonacatepec. Angustias, lo mismo que Bárbara, adopta el papel de dominadora de los hombres.

Doña Bárbara se aprovecha de su poder sobre los hombres, para enriquecerse. Después de que Lorenzo Barquero cae bajo su dominio, ella lo echa de la casa y se apropia de su hato, con la complicidad del coronel Apolinar, el cacique de la región. Una vez que Bárbara ha aprendido todos los trucos legales de éste, ya no lo necesita y causa su misteriosa desaparición. No puede tolerar la idea de que un hombre ejerza dominio sobre ella. Despiadada en su deseo de conseguir la independencia femenina por medio del poder, destruye a todos sus enemigos, con su belleza, su brujería y sus asesinos. Su odio a los hombres adquiere un tinte de desprecio, al darse cuenta de que sabe manejar la reata y la pistola, como cualquier hombre. Lo mismo aconteció a doña Bárbarà, cuando llegó a los llanos de Santos Luzardo.

La lucha personal de Angustias Farrera contra los hombres coincide con sus deseos de participar en la Revolución, para lograr 
la regeneración de los pobres. Poco después de salir de Real de Animas, la "coronela" y su banda se encuentran con Efrén y su pandi1la. Después de una breve escaramuza, toman preso a Efrén, y Angustias se venga del fanfarrón donjuanesco mandando que le corten los órganos genitales. ${ }^{7}$ En su marcha por los Estados de Guerrero y Morelos, la "coronela" Farrera va cobrando a diario más poder y más fama. Durante el saqueo del pueblo de Tepaltzingo, el Güitlacoche "encuentra" un hermoso traje de charro que se destina a sí mismo y un juego completo de ropa de mujer que of rece a su "coronela". De acuerdo con su actitud rebelde contra todo lo que refleja la subordinación de la mujer al hombre, Angustias rechaza la ropa fina y manda al Güitlacoche que le dé su traje de charro. Antes de ponerse el sombrero, la Negra le arranca una medalla de Nuestro Señor de Chalma y ordena al Güitlacoche que le encuentre una medalla de Nuestra Señora de Guadalupe porque "yo no necesito machos que me cuiden." 8

De la misma manera que el coronel Apolinar enseña a doña Bártara las ventajas de servirse de la ley para sus propios fines ambiciosos, Concho, el joven arriero, explica a su "coronela" las ventajas de los consejos de guerra, para juzgar a los prisioneros. La Negra Angustias alcanza su mayor poder, tanto de cabecilla revolucionaria como de campeona de las mujeres, en Cuautla. Encontrándose una noche en una cantina con varios grupos zapatistas, no sólo se defiende de esos temibles brutos sino que aun los domina. A pesar de las burlas de sus compañeros, el Güitlacoche no se atreve a contrariar a su "coronela", cuando ella le manda que pague su deuda a una prostituta. Según el razonamiento de la mulata, no es el deseo de someterse a los hombres sino el hambre lo que impulsa a estas mujeres a ofrecerse. Su actitud evoca el comentario de un oficial:

"-Lástima que el más hombre de todos sea mujer." $\theta$

Es interesante notar que las dos heroínas se dejan vencer por hombres cultos. En la novela venezolana, Santos Luzardo se vale de las mismas leyes que doña Bárbara ha hecho para dominar a la cacica. Ella, acostumbrada a defender lo suyo con fuerza, se siente impotente ante la ley.

-i Que este papel, este pedazo de papel que yo puedo arrugar y volver trizas, tenga fuerza para obligarme a hacer lo que no me da la gana! 
Pero estas rabiosas palabras, además de encono, expresaban también otra cosa: un acontecimiento insólito, un respeto que doña Bárbara nunca había sentido. 10

Este respeto a Santos Luzardo también se debe al despertar de los instintos femeninos de Bárbara, largamente reprimidos. En su imaginación se le presenta la ocasión de enamorarse de un hombre que se parece al único amor de su vida, Asdrúbal, el blanco que en la piragua le enseñaba a leer y a escribir, antes de ser asesinado al rebelarse la tripulación.

Durante estas lecciones, en las cuales Asdrúbal ponía gran empeño, las letras que ella hacía llevándole él la mano, los acercahan demasiado. 11

Encontramos una situación paralela, en la novela mexicana. Al ver una proclama revolucionaria que está pegada en una pared, Angustias se lamenta en su propia sencilla manera de no saber leer:

- Hay que saber para saber... Bien dijo el catrin que ayer nos echó el discurso. Nosotros así como estamos no semos para el caso... i Hay que saber para saber! 12

Dirigiéndose al Güitlacoche, ordena:

-Mira, capitán, p'mañana quero que me tengas arreglado un maistro que me enseñe a ler...13

Su capitán no tarda en llevarle, para maestro, a un muchacho enclenque y tímido, hijo mimado de la clase media, recién recibido de maestro en la capital: Manuel de la Reguera y Pérez Cacho. Aunque es un tipo poco atractivo para las mujeres, la "coronela" pronto se enamora de él. Quizás es su propia timidez lo que logra desconcertarla. La mulata hasta se ruboriza cuando, en una escena que nos hace pensar en Asdrubal,

... el profesor echó su busto sobre el respaldo de la silla; luego puso su mano larga y pálida sobre la regordeta diestra de la mulata y ambos cabalgaron sobre la afilada punta de un lápiz, en ruta retorcida, complicada, infinita...14 
Poco a poco las dominadoras van cambiándose en mujeres. Doña Bárbara se viste de mujer por primera vez en muchos años, $y$ todos murmuran que se ha enamorado del "doctor". Se reforma por completo. Para ganarse el amor de Santos Luzardo, entrega al juez las plumas de garza y el cadáver de Balbino Paiba, quien las había robado al "doctor". Sin embargo, ya es muy tarde para arrepentirse. A pesar de sus sueños, no puede aspirar al amor de Luzardo que ya se ha consagrado a Marisela, la propia hija abandonada de la cacica.

Angustias también se vuelve más femenina al entrar en contacto con el hombre culto. Limpia el cuarto donde Manolo le da las clases pone un manojo de flores en la mesa y vuelve a vestirse de mujer. Cuando las tropas revolucionarias abandonan a Cuernavaca por la inminencia del asalto de los federales, Angustias prefiere quedarse con Manolo, en la.ciudad. Pero al entrar en Cuernavaca las tropas del gobierno, Angustias monta a caballo, secuestra a Manolo y se lo lleva a su pueblo natal. Ahi se cumple su deseo de alcanzar la verdadera femineidad, entre los mismos arbustos donde ella contemplaba los festejos eróticos de sus cabras. El cambio brusco en la vida de Manolo, lo obliga a decidirse. Al darse cuenta de que Angustias ha llegado a reconciliarse con su propio sexo, Manolo se resuelve a aprovecharse de la reputación de la Negra. Consumado el matrimonio, se le òlvida a Angustias todo su pasado violento y está preparada para aceptar la abnegada vida de la mujer mexicana.

Entonces - dijo la Angustias serenamente-, tú serás el que ordene; yo estoy dispuesta a obedecerte. ${ }^{15}$

Manolo lleva a Angustias a México, donde consigue un excelente empleo oficial valiéndose de los términos de la amnistía. Todas las semanas Manolo tiene que llevar a su esposa al Palacio Nacional, para comprobar que ya no es "coronela". Asegurado el empleo, Manolo visita a su esposa solamente de vez en cuando, aun después de que ella le da un niño. Sin embargo, tal es la transformación de Angustias, que acepta la situación y hasta agradece a Manolo sus visitas más y más raras.

De la misma manera que se desarrollan paralelamente las vidas de Bárbara y Angustias, se extiende este paralelismo hasta el modo de 
poner fin a sus historias: el truco literario de referirse a temas apenas presentados en las primeras páginas de los dos libros. Al comienzo de Doña Bárbara, Gallegos nos dice, refiriéndose a su protagonista, que "su origen se perdia en el misterio de las tierras." 16 En las últimas páginas de la novela, la "guaricha", quien se crió en una piragua que viajaba por el Orinoco y sus afluentes, siente la llamada sobrenatural de la naturaleza. Al afirmar que "las cosas vuelven al lugar de donde salieron", ${ }^{17}$ Bárbara nos anuncia su pronta desaparición, la cual, unida a la falta de noticias sobre su inicial aparición en escena, encuadra la novela en un marco de misterio.

La noticia corre de boca en boca: ha desaparecido la cacica del Arauca.

Se supone que se haya arrojado al tremedal, porque hacia allá la vieron dirigirse, con la sombra de una trágica resolución en el rostro, pero también se habla de un bongo que bajaba por el Arauca y en el cual alguien creyó ver una mujer. 18

Rojas González enmarca su novela de una manera aún más obvia. Las primeras palabras del libro, "lavaba y cantaba" (refiriéndose a Angustias, desde luego), se repiten en la última página. La única diferencia consiste en que entonces lavaba en el "ojo de agua", en el cerro, y ahora está lavando en una azotehuela de la. capital. Toda su vida de contrastes se anticipa por el epígrafe del libro, una estrofa de las inmortales redondillas de Sor Juana:
Siempre tan necios andảis, que con desigual nivel a una culpáis por crüel y a otra por fácil culpáis.

No obstante la misma disposición final de las dos protagonistas en su vuelta a la nada de donde surgieron, hay una significativa diferencia. Doña Bárbara, después de una desagradable serie de experiencias sexuales, se ve defraudada cn su amor por Santos y acaba por desaparecer. En cambio, Angustias, no habiendo conocido más que a un hombre, Manolo, acepta su situación resignadamente. En los dos casos, se repite la historia de la deificación del hombre blanco por la mujer de la raza conquistada. 
A pesar de que Rojas González se dejó influir por Gallegos en stus descripciones de los orígenes, las causas de rebeldía, el dominio sobre los hombres, la derrota por el hombre culto y la vuelta a la nada de su protagonista, La negra Angustias tiene su propio valor literario.' En la novela venezolana, el estudio psicológico de una mujer se complementa por la barbarie, el misterio y la poesía de los llanos, simbolizado todo en el nombre de la protagonista, doña Bárbara. De análoga manera, el carácter de la negra Angustias se desarrolla entre el ambiente turbulento de la Revolución mexicana, de la cual su nombre también es muy simbólico. Las escenas de saqueo y de taberna, pueden compararse con las mejores de Los de abajo. La actitud resentida y desconfiada de los soldados analfabetos frente a los pedantes discursos de Pérez Gómez nos recuerda la enemistad con que los hombres de Demetrio Macías saludan a Luis Cervantes, en la obra maestra de Azuela, y de toda la campaña de Pedro el ex profesor de Tierra caliente de Jorge Ferretis. Sin embargo, Rojas González revela en este libro más simpatía y comprensión por los revolucionarios, que Azuela o Ferretis. Como López'y Fuentes, presenta de un modo simpático a varios personajes que van rodando en la "bola": Concho el arriero; Aniceto Cruz, el viejo campesino que ofrece a la causa a sus cuatro hijos y tres yernos, pero sólo a condición de que les dejen seguir su riña tradicional con la familia Muñoz; el general Anacleto Trujillo, quien se alistó porque tenía miedo de ser acusado de un crimen que no había cometido; Rubén Dosamantes, quien mató al hijo del hacendado en una disputa por causa de una mujer; y una mujer que busca desesperadamente a su hijo.

Esta presentación de la Revolución, que sirve de fondo para el desarrollo del fuerte personaje que es Angustias Farrera, da a La negra Angustias la distinción de ser la obra más importante de Rojas González: verdadera contribución a la literatura mexicana y digno vástago de una de las mejores novelas hispanoamericanas.

Seymour Menton, University of Kansas. 


\section{NOT A S}

1 Rómulo Gallegos, Doña Bárbara, (Buenos Aires: Espasa-Calpe; 1947), p. 214.

2 Ibid., p. 27.

3 Ibid., p. 34.

4 Ibid., p. 27.

5 Ibid., p. 31.

6 Ibid., p. 32.

7 El mismo castigo impuesto al tendero mujeriego de Germinal, de Zola.

8 Francisco Rojas González, Ia negra Angustios, 2* ed. (México: E. D. I. A. P. S. A., 1948), p. 108.

9 Ibid., p. 129.

10 Gallegos, op. cit., pp. 130-131.

11 Ibid., p. 28.

12 Rojas González, op. cit., p. 157.

13 Ibid.

14 Ibid., p. 171.

15 Ibid., p. 207.

16 Gallegos, op. cit., p. 27.

17 Ibid., p. 214.

18 Ibid., pp. 298-299.

\section{BIBLIOGRAFIA}

1 Rómulo Gallegos, Doña Bárbara, (Buenos Aires: Espasa-Calpe, 1947).

2 Francisco Rojas González, La negra Angustias, $2^{4}$ ed. (México: E. D. I. A. P. S. A., 1948). 